\title{
Sedentary prey facing an acute predation risk: testing the hypothesis of inducible metabolite emission suppression in zebra mussels, Dreissena polymorpha
}

\author{
Andrzej Antoł · Justyna Kierat • Marcin Czarnoleski
}

Received: 17 September 2016/Revised: 16 February 2017/ Accepted: 26 February 2017/Published online: 7 March 2017 (C) The Author(s) 2017. This article is published with open access at Springerlink.com

\begin{abstract}
It takes time before a defensive phenotype can be effectively developed, which handicaps sessile bivalves exposed to acute predation risks. In a laboratory experiment, we examined whether predation threats induce zebra mussels to limit metabolic rates, serving as a fast-response defence that reduces the chances of chemical detection by predators. We measured the respiration rate of mussels exposed to predation treatments (fish fed zebra mussels, fish fed chironomids, crushed zebra mussels) and to predationfree conditions, and we tested the effect of these treatments on attachment strength and aggregation. Compared with the predation-free controls, all mussels in the predation treatments tended to initially have suppressed metabolic rates. The rate of metabolism increased over time in all treatments, but only in the presence of fish fed chironomids was the increase significantly greater than in the control. Attachment strengths and aggregation rates were similar for all
\end{abstract}

Guest editors: Manuel P. M. Lopes-Lima, Ronaldo G. Sousa, Lyuba E. Burlakova, Alexander Y. Karatayev \& Knut Mehler / Ecology and Conservation of Freshwater Bivalves

Electronic supplementary material The online version of this article (doi:10.1007/s10750-017-3144-0) contains supplementary material, which is available to authorized users.

A. Antoł · J. Kierat · M. Czarnoleski $(\bowtie)$ Institute of Environmental Sciences, Jagiellonian University, Gronostajowa 7, 30-387 Kraków, Poland

e-mail: marcin.czarnoleski@uj.edu.pl treatments after 7 days. Our results provide the first evidence of predation-induced changes in zebra mussel metabolic rates. We suggest that mussels respond differently to different types of predation threats. Immediately after receiving predation cues, they react promptly by lowering their production of metabolites, but over time, they re-adjust their response to the actual predation threat present.

Keywords Aggregation - Attachment - Antipredator strategy · Chemical detection - Inducible defences . Metabolic rate $\cdot$ Metabolic suppression - Predatorprey interactions $\cdot$ Zebra mussels

\section{Introduction}

Spatiotemporal fluctuations in predation risks drive the evolution of inducible defences in prey species (Ydenberg \& Dill, 1986; Clark \& Harvell, 1992). An effective induction of a defensive phenotype requires the prey to assess the predation risk (Gabriel et al., 2005), which can involve recognizing predator diets (Brown \& Dreier, 2002); sensing the type (Lowen et al., 2013), size (Kobak et al., 2010) and abundance of predators (Van Buskirk \& Arioli, 2002); or estimating the spatial position relative to a predator (Cooper, 2006). A time lag between detecting a predation cue and developing a defensive phenotype is critical to the effectiveness of the defence and thus plays a role in the evolution of inducible defences 
(Czarnoleski \& Muller, 2014). The importance of response time becomes apparent when we consider sessile bivalves, immobilized by their byssal attachment to a rock and therefore unable to quickly move away to escape from predators. Instead, when faced with predation cues, sessile bivalves often change their spatial position to form clumps with conspecifics (Côté \& Jelnikar, 1999) and intensify the production of byssus (Cheung et al., 2009) and shell material (Czarnoleski et al., 2006). All of these responses require energy to fuel anabolic processes, mainly protein synthesis, and it can take days or weeks before a defensive phenotype is effectively developed, which is apparently a handicap for sessile bivalves exposed to acute predation risks.

Here, in a series of experiments on zebra mussels (Dreissena polymorpha), we examined whether an acute predation risk elicits a fast-response defence in mussels that reduce their detection by predators. Based on the findings of Czarnoleski \& Muller (2014), we hypothesized that zebra mussels would reduce their emission of disclosing metabolites when they receive cues about foraging predators. Upon foraging, common predators of bivalves, such as fish and crustaceans, use prey metabolites to sense the location of their prey (Hazlett, 1994; Weissburg and ZimmerFaust, 1994; Weissburg et al., 2002), but the hypothesis of inducible metabolite emission suppression (HIMES) has rarely been addressed by earlier studies (but see Weissburg and Zimmer-Faust, 1994; Smee \& Weissburg, 2006; Czarnoleski \& Muller, 2014). Over the last two centuries, Ponto-Caspian zebra mussels have expanded to diverse environments in Europe and North America (http://www.europe-aliens.org/), facing a variety of pressures from local predators (Czarnoleski et al., 2010a). It is believed that without an effective inducible defence, this invasion might have been less spectacular and may have not been possible at all (Czarnoleski et al., 2006). The byssus of zebra mussels has been shown to reduce the risk of dislodgement by predatory fish (Kobak \& Kakareko, 2011), suggesting that strengthening the byssal attachment might be a crucial part of an inducible defence strategy in this species. Surprisingly, experiments on zebra mussels found two contradictory patterns: the presence of non-feeding roach increased the strength of byssal attachments (Kobak et al., 2010), but the presence of crushed conspecifics (Czarnoleski et al., 2010b) or crayfish fed conspecific mussels
(Czarnoleski et al., 2011) resulted in weaker byssal attachments. Czarnoleski et al. (2011) speculated that cues about the presence of fish and the presence of injured conspecifics might indicate two different threats. The presence of a predatory fish in the absence of signs of crushed zebra mussels signals a predator that is not currently preying upon conspecifics, which suggests that such a predator does not impose an immediate danger (e.g. it may be feeding on other prey or is not hungry). This cue suggests that there is sufficient time for initiating energetically costly and timeconsuming responses, such as the strengthening of byssal attachments, which help protect the mussel against future predation events. In contrast, injured conspecifics signal an immediate threat of predationa predator is actively preying on conspecifics. The time-consuming process of strengthening byssal attachments would not be effective in this situation, and an effective option would be an immediate suppression of the emission of disclosing metabolites. As byssal synthesis requires a high level of energy expenditure, an inevitable long-term side effect of the metabolic suppression is decreased byssal attachment strength. To test the HIMES predictions, we measured attachment strength, degree of aggregation and oxygen consumption in zebra mussels exposed to four predation treatments: (i) roach fed zebra mussels, (ii) roach fed chironomid larvae, (iii) crushed conspecific mussels, and (iv) a predation-free environment. We expected that, relative to our predation-free mussels (treatment iv), mussels in treatment ii would increase their byssal attachment strength and degree of aggregation, which would result in higher metabolic rates due to the increase in anabolic processes. In addition, we predicted that mussels from treatments $\mathrm{i}$ and iii would be characterized by slower metabolic rates, which would be followed by reduced byssal attachment strength, with an unaltered or reduced degree of aggregation.

\section{Materials and methods}

Animals

Zebra mussels were collected in autumn 2011 in Dgał Wielki Lake (Mazurian Lakes, Poland). Roach ( $R u$ tilus rutilus L.) were obtained from the Department of Ichtyobiology and Fisheries, University of Agriculture 
in Krakow. All roach exceeded a body length of $16 \mathrm{~cm}$, which is regarded as the size threshold at which roach becomes capable of feeding on zebra mussels (Prejs et al., 1990). All animals were maintained in a stock room in the Institute of Environmental Sciences (Jagiellonian University, Kraków, Poland) at $11^{\circ} \mathrm{C}$ and with a $12: 12 \mathrm{~h}$ photoperiod. Prior to the experiments, roach were regularly fed with frozen chironomid larvae, and the zebra mussels were not fed. Three weeks before the experiments, animals were transferred from a stock room to an experimental room at a temperature of $17^{\circ} \mathrm{C}$; the light conditions were as in the stock room. The physiological activity of experimental animals was primed via controlled feeding. Zebra mussels were placed into large tanks and fed a suspension of dried Chlorella sp. (Aquafauna BioMarine Inc., USA). Roach were divided into a group fed frozen chironomids and a group fed live zebra mussels.

\section{Experiment 1: aggregation and attachment}

The experiment on inducible changes in aggregation and attachment strength was conducted in eight tanks. Each tank was filled with 701 of tap water and was constantly aerated. We placed ten Plexiglas cubic boxes (Fig. 1) into each tank. Each box consisted of detachable walls $(70 \times 70 \mathrm{~mm})$ held in place by rubber bands. The boxes were left intact in the tanks for $24 \mathrm{~h}$, which allowed a biofilm to build up on the



Fig. 1 An example of an experimental Plexiglas cube used in Experiment 1 to study the aggregation and attachment of zebra mussels. Each box consisted of five detachable walls $(70 \times 70 \mathrm{~mm})$ and was covered with a square piece of mesh held in place with a rubber band to prevent the mussels from escaping surface of walls. After this, we placed eight zebra mussels (shell length, 8-12 mm) into each box, spacing them evenly on the bottom surface. The boxes were covered with a square piece of mesh held in place with a rubber band to prevent the mussels from escaping. The mesh was made of the soft curtain material with $5 \times 5 \mathrm{~mm}$ square holes (Fig. 1). Mussels in all tanks were acclimated to the control conditions (pure water) for $24 \mathrm{~h}$. After this, each tank was allocated to one of the four predation treatments (i-iv), with two tanks per treatment. Tanks in treatments $i$ and ii harboured roach. In treatment $i$, there was a single roach (mass, $459 \mathrm{~g}$ ) in one tank and two roach (masses, 93 and $128 \mathrm{~g}$ ) in the second tank. In treatment ii, there was a single roach (mass, $303 \mathrm{~g}$ ) in one tank and two roach (masses, 55 and $173 \mathrm{~g}$ ) in the second tank. This maintained comparable roach biomasses in both treatments, which controlled for the potential effect of predator size on the amount of predation cues received. The roach were provided with equal amounts of soft tissue of either live zebra mussels (treatment i) or frozen chironomid larvae (treatment ii). One ration of zebra mussel $(8-15 \mathrm{~mm})$ weighed $32.5 \mathrm{~g}$, and one ration of chironomids weighed $7.8 \mathrm{~g}$. Prior to the experiment, we estimated that $32.5 \mathrm{~g}$ of mussels contained an average of $7.8 \mathrm{~g}$ of soft tissue, the equivalent of our chironomid rations. This procedure involved 25 randomly sampled mussels with shell lengths from 8 to $15 \mathrm{~mm}$. The mussels were weighed, and after the removal of soft tissue, their shells were weighed. These data were used to estimate what proportion of the body mass of intact mussels was made up of soft tissue mass. Treatment iii was established following the methods of Czarnoleski et al. (2010b). In brief, $32.5 \mathrm{~g}$ of live mussels ( $8-5 \mathrm{~mm}$ length) was homogenized in a mortar and mixed with water. The mixture was strained and added to an experimental tank with zebra mussels. Treatment iv contained pure tap water. In the tanks for treatments i, ii and iii, we released freshly prepared predation cues twice daily, in the morning and evening. For cleaning purposes, in each tank, we replaced 431 of water with fresh water daily, just before the evening release of predation cues.

The experiment ended 7 days after first exposing the mussels to the treatment conditions. The walls of each box were disassembled and examined to assess the aggregation of mussels and the strength of their attachment. We regarded a mussel to be part of a 
clump if its shell was in a direct physical contact with a shell of at least one other mussel. For each box, we calculated an aggregation index. We counted the aggregated mussels in each clump and then subtracted 1 , assuming that the mussel at the centre of the group might not actively take part in the process of aggregation. Then, we summed the results of this calculation for all the clumps in a box. Note that our aggregation index values increased with the total number of aggregated mussels, and if two boxes had even numbers of aggregated mussels, the box with one large clump received a higher index value than the box with multiple smaller clumps. This property of our index was likely to be biologically relevant because individual mussels in a large clump should better resist dislodgement by predators than individual mussels in a small clump.

Following Czarnoleski et al. (2010b), we measured the attachment strength of the byssus with an electronic force gauge (FG-5000A, Lutron Electronic Enterprise Co., Taiwan) assembled on a stand with a hand-operated wheel. The walls of boxes with attached mussels were placed on a counter-top, with the mussels pointing upward. A battery clip attached to the gauge via a flexible metal string was clipped to a mussel. We measured the maximum force $( \pm 0.01 \mathrm{~N})$ needed to pull the mussel away from the attachment site by slowly raising the vertical column with the gauge until the mussel became completely detached. Mussels attached in corners or to other mussels were not measured. The length of each mussel was measured with a Vernier calliper $(0.1 \mathrm{~mm})$.

\section{Experiment 2: oxygen consumption}

Following the end of Experiment 1, we maintained our treatments (i-iv) in the experimental tanks, and water from these tanks was used to examine the oxygen consumption of zebra mussels exposed to our treatment conditions. Oxygen measurements were conducted every 24 h over 12 consecutive days (hereafter, respiration sessions). For each session, we sampled 12 zebra mussels in the morning. The animals originated from the same pool of animals as the ones used in Experiment 1, but they were not involved in Experiment 1. A shell of each mussel was gently cleaned with filter paper, and shell length was measured to the nearest $0.1 \mathrm{~mm}$ with an electronic calliper. To minimalize the effect of body size on our metabolic measurements, only individuals of a uniform size (10-12 mm) were chosen for the experiment. The mussels were placed individually into $50-\mathrm{ml}$ bottles filled with $40 \mathrm{ml}$ of water originating from one of our experimental tanks (each day we altered the source tank in a treatment, so in total, each of the two tanks per treatment contributed equal numbers of water samples). Each bottle with a mussel had an assigned reference bottle without a mussel, which contained water from the same treatment and served as a base line. Bottles with mussels were connected in a random order to a closed-system respirometer (MicroOxymax, Columbus Instruments, USA), with each reference bottle placed next to the corresponding bottle with an experimental animal. All bottles were placed in thermally controlled cabinets, which kept the mussels at a stable temperature $\left(18.5 \pm 0.14^{\circ} \mathrm{C}\right.$; mean $\left.\pm \mathrm{SD}\right)$, with constant light. Note that this temperature deviated by $1.5^{\circ} \mathrm{C}$ from the temperature in experiment 1 , but this deviation was unlikely to cause any qualitative differences in the results of experiment 1 and 2. The rate of oxygen consumption $(\mu \mathrm{l} / \mathrm{h})$ in the air of each bottle was estimated for each of five consecutive time intervals, with each interval lasting $2 \mathrm{~h} 33 \mathrm{~min}$. To calculate the metabolic rate of a mussel, the rate of oxygen consumption in a reference bottle was subtracted from the rate measured in the respective bottle with a mussel. This allowed us to remove potential effects of microorganisms in the water on our metabolic measurements of the mussels.

Statistical analysis

We analysed the data using general linear mixed modelling (GLMM) in the R package (R Core Team, 2015) with the lme4 and lmerTest packages (Bates et al., 2015; Kuznetsova, 2016). In the GLMM for attachment strength and the aggregation index (Experiment 1), treatment group (i-iv) was a fixed factor and experimental tank was a random factor nested within a treatment. The model for attachment strength also considered mussel length as a numerical covariate. The attachment strength and mussel length were log-transformed prior to analysis. In the GLMM for oxygen consumption, treatment group was a fixed factor, and respiration session was a random factor. As the rate of oxygen consumption of each mussel was measured repeatedly over five time intervals, the model also included the experimental unit (mussel) as 
another random factor and time as a covariate. Additionally, this improved the test of our hypothesis by controlling for any random effects due to differences in our experimental units, such as betweenmussel differences in physiological state or differences in the mass of metabolically active tissues, and for residual differences in the metabolic activity of microorganisms associated with mussels or living in the water. Additionally, the model considered an interaction between the treatments and time. The random structure of the model included the estimation of a regression intercept and a slope at each level of our random factors (i.e. for each experimental unit and each respiration session). This model structure was selected based on the Akaike information criterion from a set of competing models. All models subjected to this comparison had the same fixed factors, but they differed in the structure of their random components. The mean squares were estimated with a REML method. Oxygen consumption was log-transformed prior to the analysis. To explore the nature of the interaction between treatment and time, we performed a post hoc analysis of the best model, comparing the slopes between all treatments using a general linear hypothesis test (multcomp package, Hothorn et al., 2008).

\section{Results}

The results of Experiment 1 show that larger mussels produced stronger attachments $\left(p=0.02, F_{1,224}=\right.$ 5.20; Table 1). Among our four treatment groups, mussels from the predation-free group developed the weakest byssal attachments and had the lowest aggregation index values (Figs. 2, 3), but the overall effects of our treatments were not statistically significant in either of the two analyses $\left(P=0.3, F_{3,4}=\right.$ 1.76 and $P=0.19, \quad F_{3,4}=2.61$, respectively; Table 1, Online resource 1 and 2).

The results from Experiment 2 show that following exposure to experimental treatments, mussels in all groups steadily increased their rate of oxygen consumption over time $\left(P<0.01, F_{1,11}=40.44\right.$, Table 1; Fig. 4). Our treatments had significant impacts on the metabolic rates of mussels, but this effect was time-dependent, as indicated by the significant time $\times$ treatment interaction $(P=0.01$, $F_{3,129}=3.85$, Table 1 , Online resources 3 ). Our post hoc comparison of these rates, which assessed the time $x$ treatment interaction, revealed that the metabolic rate increased significantly faster in mussels exposed to cues from roach fed chironomids (group ii) than in the control group. As shown in Fig. 4, following exposure to the treatment conditions, mussels in treatment ii had the lowest metabolic rates of all the treatments groups, but overall, all mussels from our predation treatments (i-iii) tended to have lower metabolic rates than mussels in the predation-free control group (iv). After a steady increase in metabolic rates in all treatments, mussels in treatment group ii reached the highest metabolic rate among all treatment groups.

\section{Discussion}

After exposure to our experimental treatments, all zebra mussels responded in a similar manner, with an initially slow oxygen consumption rate, followed by a steady increase in oxygen consumption over time. It is possible that the mussels were regaining their filtering capacity after a suppression caused by the physical disturbance, but it is likely that this initial suppression reveals an important element of a general antipredator response aimed at reducing the emission of disclosing metabolites. Supporting this idea, our treatment groups differed in the rates at which the metabolic rates of the mussels increased over time. Consistent with a general prediction of the HIMES regarding predator-induced metabolic suppression, all mussels that received predation cues (treatments i-iii) initially showed a stronger tendency to maintain a lower metabolic rate than mussels in the predation-free control group (iv). Contradictory to our predictions, the greatest suppression occurred in our 'low predation risk' treatment (ii), where mussels received cues about roach feeding on chironomids, rather than in treatments (i) and (iii), where mussels were exposed to effluents from crushed conspecifics, a reliable sign of an immediate risk of predation. However, the recovery of metabolic functions over time occurred at the fastest rate in the 'low predation risk' mussels (ii), so at the end of our respiratory measurements, these mussels were consuming oxygen at the fastest rate among all treatments. Apparently, the initial suppression of metabolism in treatment ii was compensated for by the subsequent increase in metabolic rate. We can only speculate on the origin of this complex pattern of 
Table 1 Results of three General Linear Mixed Models that compared attachment strengths, aggregation indices and respiration rates of zebra mussels among four predation treatments (i-iv)

\begin{tabular}{|c|c|c|c|c|c|c|}
\hline Effect & SS & MS & Numerator df & Denominator df & $F$ & $P$ \\
\hline \multicolumn{7}{|l|}{ Attachment strength } \\
\hline Treatment & 1.84 & 0.61 & 3 & 4.00 & 1.76 & 0.29 \\
\hline Mussel length & 1.81 & 1.81 & 1 & 224.40 & 5.20 & 0.02 \\
\hline \multicolumn{7}{|l|}{ Aggregation index } \\
\hline Treatment & 12.59 & 4.20 & 3 & 4.07 & 2.61 & 0.19 \\
\hline \multicolumn{7}{|c|}{ Consumption rate of $\mathrm{O}_{2}$} \\
\hline Treatment & 0.56 & 0.19 & 3 & 131.28 & 2.38 & 0.07 \\
\hline Time & 3.15 & 3.15 & 1 & 11.00 & 40.44 & $<0.01$ \\
\hline Treatment $\times$ Time & 0.90 & 0.30 & 3 & 128.87 & 3.85 & 0.01 \\
\hline
\end{tabular}

The table reports fixed factors, but full models also considered random effects, experimental tanks in the models for attachment strength and aggregation index, and mussel and respiration session in the model for $\mathrm{O}_{2}$ consumption rate. Time in the latter model is a continuous variable, which measured the time of respiration measurements since the exposition of mussels to experimental treatments

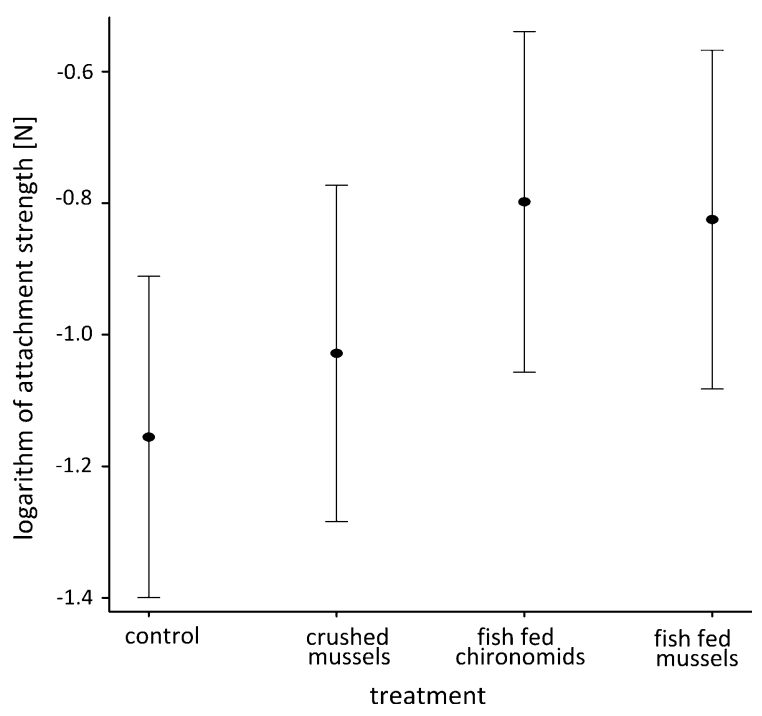

Fig. 2 After $24 \mathrm{~h}$ of attaching without predation cues and 7 days of exposure to cues, there were no differences in the attachment strength of zebra mussels among the four predation treatments. The graph shows the values predicted by the General Linear Mixed Model (results of which are described in Table 1). Error bars show $95 \%$ confidence intervals

inducible changes in metabolic rates. Based on the predictions of the HIMES, we envision that an antipredator response by mussels might consist of two consecutive phases. In the initial phase, immediately after detecting cues about the presence of predators, mussels indiscriminately suppress metabolic activity to reduce detection by predators. In the

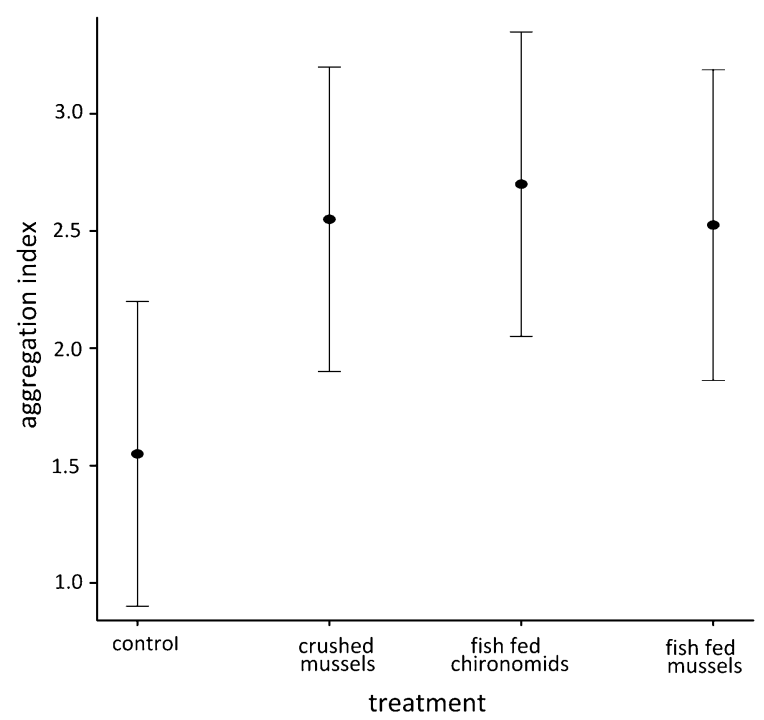

Fig. 3 After $24 \mathrm{~h}$ of attaching without predation cues and 7 days of exposure to cues, there were no differences in the aggregation indices of zebra mussels among the four predation treatments. The graph shows the values predicted by the General Linear Mixed Model (results of which are described in Table 1). Error bars show $95 \%$ confidence intervals

subsequent phase, the sampling of environmental cues over time allows mussels to re-adjust their defensive response to the actual predation threat. For example, experiencing no signs of direct predation on conspecifics, as was the case in treatment ii, increases the expected benefits gained from investing in increased attachment strength and shell resistance. On the other 


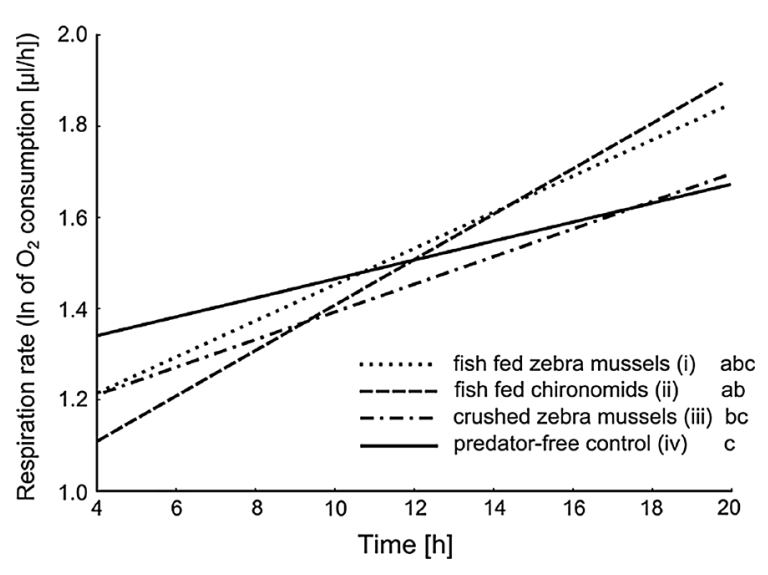

Fig. 4 The relation between zebra mussel respiration rate and time from the beginning of the measurement period. Intercepts and slopes of treatments have been estimated with the GLMM detailed in Table 1. The regression equations for the particular treatments are (i) fish fed zebra mussels, $y=1.05+0.04 x$; (ii) fish fed chironomids, $y=0.91+0.05 x$; (iii) crushed zebra mussels, $y=1.09+0.03 x$; (iv) predation-free control $y=1.25+0.02 y$. Regression slopes were compared between treatments with a post hoc test. The statistical significance of the differences in slopes is indicated by different letters $(a-c)$

hand, signs of direct predation on conspecifics, as was the case in treatments $\mathrm{i}$ and iii, decrease the expected benefits gained from investing in greater attachment strength and crush resistance. We stress that these hypotheses should be rigorously tested, especially that we did not detect significant effects of predation cues on the attachment strength. It is unlikely that the responses predicted by the HIMES are effective against bird predation, but they should be effective in confrontations with other predators, such as crustaceans and fish, which have the physiological capacity to localize zebra mussels based on chemical information (Atema, 1980; Hara, 1994; Lee \& Meyers, 1996). In fact, experiments on crayfish show that these predators use chemical detection to sense dead (Hazlett, 1994) and living zebra mussels (Czarnoleski et al., 2011). Similar information on fish, and especially quantitative data on the links between metabolic suppression and predation rates, are completely lacking, but we hope that our results will stimulate future research in this area.

If the mechanisms predicted by the HIMES actually occur, this would help explain some unexpected patterns that have been reported in earlier studies on different species of bivalves. In marine bivalves, the presence of predation cues was found to reduce byssus production and mobility in Hormomya mutabilis
(Ishida \& Iwasaki, 2003), food intake in Mercenaria mercenaria (Smee \& Weissburg, 2006) and respiration rates in Perumytilus purpuratus (Vial et al., 1992; Lopez et al., 1995). In zebra mussels, cues from injured conspecifics have been found to reduce mobility (Toomey et al., 2002; Czarnoleski et al., 2010b), clearance rates (Naddafi et al., 2007; Naddafi \& Rudstam, 2014) and attachment strength (Czarnoleski et al., 2010b, 2011), and to bias filter-feeding towards easy-to-digest foods (Naddafi et al., 2007). In our experiments, the degree of aggregation and attachment strength of zebra mussels were not significantly affected by the treatment conditions. This result is inconsistent with the results of earlier experiments on zebra mussels, which either showed an increase in attachment strength and the degree of aggregation in the presence of roach (Kobak et al., 2010) or a decrease in attachment strength in the presence of cues from injured conspecifics (Czarnoleski et al., 2010b). Predator-induced changes in byssus production and the degree of aggregation have also been found in other bivalves (Côté \& Jelnikar, 1999; Nicastro et al., 2007; Cheung et al., 2009; Chiu et al., 2011; Lowen et al., 2013). Most likely, this inconsistency indicates differences in experimental designs, especially the fact that our present design had, for logistical reasons, only two fish tanks per treatment, which decreased the statistical power for detecting significant differences. Nevertheless, the inconsistency we found is worth additional attention as it may also indicate some overlooked nature of antipredator responses. In our experiment, mussels were allowed to re-establish their byssal attachment for $24 \mathrm{~h}$ prior to their exposure to predation cues, but in earlier studies, the exposure to predation cues was immediate. Consequently, given that the a large portion of byssal threads are already produced by zebra mussels in the first day following detachment (Czarnoleski et al., 2010b), our experimental design most likely provided mussels with the information about predation risks after resources started to be channelled to byssal production, whereas in earlier designs, mussels were informed about predation risks before initiating in any defensive responses. In this regard, our experimental design, despite decreasing the chances of detecting significant effects, is more similar to natural conditions, where mussels are firmly attached to the substratum. The responsiveness of prey to predation cues is likely to be context-dependent. For example, predation has been shown to stimulate zebra 
mussels and pulmonate snails to produce heavier shells but only in environments deficient in calcium, where molluscs typically have thinner shells (Rundle et al., 2004, Czarnoleski et al., 2006).

At this stage, we are far from a full understanding of the nature of antipredator strategies in bivalves. Although it is difficult to extrapolate discoveries from one study and apply them to the complex processes of other organisms, the crucial insights from our findings are that future studies on the antipredator strategies of sedentary bivalves must incorporate short-term behavioural responses and consider how these responses depend on the environmental context. Arguably, despite their apparent handicap due to their sedentary lifestyle, sessile bivalves have evolved an ability to cope with acute predation risks through reducing the chances of chemical detection. There are key questions that await answers. What metabolites are used in chemical detection? What spatial scale is ecologically relevant for the chemical detection and the defensive suppression of metabolite emission? What are the consequences of trade-offs between acute behavioural responses and long-term allocation responses, such as changes in byssogenesis, shell production, growth and reproduction rate? How do bivalves adjust to these consequences over their lifetime? How do these adjustments change depending on the environmental conditions? What is the role of time constraints in shaping the optimal strategy of sedentary mussels against predators?

Acknowledgements A. M. Labecka and T. Müller helped in collecting zebra mussels. The research was supported by Jagiellonian University (DS/BINOZ/INOS/757/16 and DS/ BINOZ/INOS/761/16). Comments of two anonymous reviewers helped to improve the manuscript.

Open Access This article is distributed under the terms of the Creative Commons Attribution 4.0 International License (http:// creativecommons.org/licenses/by/4.0/), which permits unrestricted use, distribution, and reproduction in any medium, provided you give appropriate credit to the original author(s) and the source, provide a link to the Creative Commons license, and indicate if changes were made.

\section{References}

Atema, J., 1980. Chemical senses, chemical signals, and feeding behavior in fishes. In Bardach, J. E., J. J. Magnuson, R. C. May \& J. M. Reinhart (eds). Fish Behaviour and Its Use in the Capture and Culture of Fishes. International Center for Living Aquatic Resources Management, Manila: 57-101.

Bates, D., M. Maechler, B. Bolker \& S. Walker, 2015. Fitting linear mixed-effects models using lme4. Journal of Statistical Software 67: 1-48.

Brown, G. E. \& V. M. Dreier, 2002. Predator inspection behaviour and attack cone avoidance in a characin fish: the effects of predator diet and prey experience. Animal Behaviour 63: 1175-1181.

Cheung, S., F. Yang, J. Chiu, C. Liu \& P. Shin, 2009. Antipredator behaviour in the green-lipped mussel Perna viridis: byssus thread production depends on the mussel's position in clump. Marine Ecology Progress Series 378: 145-151.

Chiu, J. M. Y., P. K. S. Shin, F. Y. Yang \& S. G. Cheung, 2011. Can a scavenging gastropod with a mussel conspecific diet induce anti-predator defence in the mussel Perna viridis? Journal of Experimental Marine Biology and Ecology 401: 85-88.

Clark, C. W. \& C. D. Harvell, 1992. Inducible defenses and the allocation of resources: a minimal model. American Naturalist 139: 521-539.

Cooper, W., 2006. Risk factors and escape strategy in the grasshopper Dissosteira carolina. Behaviour 143: 1201-1218.

Côté, I. M. \& E. Jelnikar, 1999. Predator-induced clumping behaviour in mussels (Mytilus edulis Linnaeus). Journal of Experimental Marine Biology and Ecology 235: 201-211. doi:10.1016/S0022-0981(98)00155-5

Czarnoleski, M. \& T. Muller, 2014. Antipredator strategy of zebra mussels (Dreissena polymorpha). From behavior to life history. In: Nalepa, T. F. \& D. Schloesser (eds). Quagga and Zebra Mussels: Biology, Impacts, and Control. Taylor \& Francis Group LLC, Boca Raton: 345-357.

Czarnoleski, M., J. Kozłowski, P. Kubajak, K. Lewandowski, T. Müller, A. Stańczykowska \& K. Surówka, 2006. Crosshabitat differences in crush resistance and growth pattern of zebra mussels (Dreissena polymorpha): effects of calcium availability and predator pressure. Archiv für Hydrobiologie 165: 191-208.

Czarnoleski, M., J. Kozłowski, K. Lewandowski, T. Müller, A. Stańczykowska \& T. Müller, 2010a. An evolutionary perspective on the geographic and temporal variability of life histories in European zebra mussels. In Van der Velde, G., S. Rajagopal \& A. B. de Vaate (eds). The Zebra Mussel in Europe. Backhuys Publishers, Margraf Publishers, Leiden: 169-182.

Czarnoleski, M., T. Müller, K. Adamus, G. Ogorzelska \& M. Sog, 2010b. Injured conspecifics alter mobility and byssus production in zebra mussels Dreissena polymorpha. Fundamental and applied limnology/Archiv für Hydrobiologie 176: 269-278.

Czarnoleski, M., T. Müller, J. Kierat, L. Gryczkowski \& Ł. Chybowski, 2011. Anchor down or hunker down: an experimental study on zebra mussels' response to predation risk from crayfish. Animal Behaviour 82: 543-548.

Gabriel, W., B. Luttbeg, A. Sih \& R. Tollrian, 2005. Environmental tolerance, heterogeneity, and the evolution of reversible plastic responses. American Naturalist 166: 339-353. 
Hara, T. J., 1994. The diversity of chemical stimulation in fish olfaction and gustation. Reviews in Fish Biology and Fisheries 4: 1-35.

Hazlett, B. A., 1994. Crayfish feeding responses to zebra mussels depend on microorganisms and learning. Journal of Chemical Ecology 20: 2623-2630.

Hothorn, T., F. Bretz \& P. Westfall, 2008. Simultaneous inference in general parametric models. Biometrical Journal Biometrische Zeitschrift 50: 346-363.

Ishida, S. \& K. Iwasaki, 2003. Reduced byssal thread production and movement by the intertidal mussel Hormomya mutabilis in response to effluent from predators. Journal of Ethology 21: 117-122.

Kobak, J. \& T. Kakareko, 2011. The effectiveness of the induced anti-predator behaviour of zebra mussel Dreissena polymorpha in the presence of molluscivorous roach Rutilus rutilus. Aquatic Ecology 45: 357-366.

Kobak, J., T. Kakareko \& M. Poznańska, 2010. Changes in attachment strength and aggregation of zebra mussel, Dreissena polymorpha in the presence of potential fish predators of various species and size. Hydrobiologia 644: 195-206.

Kuznetsova, A., P. B. Brockoff \& R. H. B. Christensen, 2016. lmerTest: tests in linear mixed effects models. $\mathrm{R}$ package version 2.0-30. https://cran.r-project.org/ package=lmerTest.

Lee, P. G. \& S. P. Meyers, 1996. Chemoattraction and feeding stimulation in crustaceans. Aquaculture Nutrition 2: 157-164.

Lopez, D. A., M. L. Gonzalez, M. V. Vial \& R. W. Simpfendörfer, 1995. Sublethal effects provoked by the presence of the predator Nucella crassilabrum (Lamarck) upon the mussel Perumytilus purpuratus (Lamarck) in Chile. Revista Chilena de Historia Natural 68: 469-475.

Lowen, J., D. Innes \& R. Thompson, 2013. Predator-induced defenses differ between sympatric Mytilus edulis and $M$. trossulus. Marine Ecology Progress Series 475: 135-143.

Naddafi, R. \& L. G. Rudstam, 2014. Predation on invasive zebra mussel, Dreissena polymorpha, by pumpkinseed sunfish, rusty crayfish, and round goby. Hydrobiologia 721: 107-115.

Naddafi, R., P. Eklöv \& K. Pettersson, 2007. Non-lethal predator effects on the feeding rate and prey selection of the exotic zebra mussel Dreissena polymorpha. Oikos 116: 1289-1298.

Nicastro, K., G. Zardi \& C. McQuaid, 2007. Behavioural response of invasive Mytilus galloprovincialis and indigenous Perna perna mussels exposed to risk of predation. Marine Ecology Progress Series 336: 169-175.

Prejs, A., K. Lewandowski \& A. Stańczykowska-Piotrowska, 1990. Size-selective predation by roach (Rutilus rutilus) on zebra mussel (Dreissena polymorpha): field studies. Oecologia 83: 378-384.

R Core Team, 2015. R: A Language and Environment for Statistical Computing. R Foundation for Statistical Computing, Vienna.

Rundle, S. D., Spicer, J. I., Coleman, R. A. Vosper, J. \& J. Soane, 2004. Environmental calcium modifies induced defences in snails. Proceedings of the Royal Society B (Suppl.) 271: S67-S70. doi:10.1098/rsbl.2003.0106

Smee, D. L. \& M. J. Weissburg, 2006. Hard clams (Mercenaria mercenaria) evaluate predation risk using chemical signals from predators and injured conspecifics. Journal of Chemical Ecology 32: 605-619.

Toomey, M. B., D. McCabe \& J. E. Marsden, 2002. Factors affecting the movement of adult zebra mussels (Dreissena polymorpha). Journal of the North American Benthological Society 21: 468-475.

Van Buskirk, J. \& M. Arioli, 2002. Dosage response of an induced defense: how sensitive are tadpoles to predation risk? Ecology 83: 1580-1585.

Vial, M. V., R. W. Simpfendorfer \& M. L. Gonzfilez, 1992. Metabolic responses of the intertidal mussel Perumytilus purpuratus (Lamarck) in einersion and immersion. Journal of Experimental Marine Biology and Ecology 159: 191-201.

Weissburg, M. J. \& R. K. Zimmer-Faust, 1994. Odor plumes and how blue crabs use them in finding prey. Journal of Experimental Biology 197: 349-375.

Weissburg, M. J., M. C. Ferner, D. P. Pisut \& D. L. Smee, 2002. Mini review ecological consequences of chemically mediated prey perception. Journal of Chemical Ecology 28: 1953-1970.

Ydenberg, R. C. \& L. M. Dill, 1986. The economics of fleeing from predators. Advances in the Study of Behaviour 16: 229-249. 